\title{
Internal Resistance in Winter Oilseed Rape Inhibits Systemic Spread of the Vascular Pathogen Verticillium longisporum
}

\author{
C. Eynck, B. Koopmann, P. Karlovsky, and A. von Tiedemann
}

First author: Agriculture and Agri-Food Canada, 107 Science Place, Saskatoon, SK S7N 0X2, Canada; second and fourth authors: Plant Pathology and Plant Protection Division, Department of Crop Sciences, Faculty of Agriculture, Georg-August University Göttingen, Grisebachstraße 6, D-37077 Göttingen, Germany; and third author: Molecular Phytopathology and Mycotoxin Research Division, Department of Crop Sciences, Faculty of Agriculture, Georg-August University Göttingen, Grisebachstraße 6, D-37077 Göttingen, Germany. Accepted for publication 2 March 2009.

\begin{abstract}
Eynck, C., Koopmann, B., Karlovsky, P., and von Tiedemann, A. 2009. Internal resistance in winter oilseed rape inhibits systemic spread of the vascular pathogen Verticillium longisporum. Phytopathology 99:802-811.

Verticillium longisporum is a vascular fungal pathogen presently threatening oilseed rape production in Europe. Systemic spread and vascular responses were studied in a susceptible ('Falcon') and a resistant genotype (SEM 05-500256) of Brassica napus. Colonization of both genotypes after dip-inoculation of the roots followed by quantitative polymerase chain reaction revealed similarities only in the initial stages of root penetration and colonization of the hypocotyl, while a substantial invasion of the shoot was only recorded in 'Falcon'. It is concluded that the type of resistance represented in SEM 05-500256 does not prevent the plant base from being invaded as it is internally expressed well after root penetration and colonization of the plant base. The morphological and

biochemical nature of barriers induced in the hypocotyl tissue upon infection was studied with histochemical methods accompanied by biochemical analyses. Histochemical studies revealed the build-up of vascular occlusions and the reinforcement of tracheary elements through the deposition of cell wall-bound phenolics and lignin. Furthermore, the accumulation of soluble phenolics was observed. Although these responses were found in vascular tissues of both genotypes, they occurred with a significantly higher intensity in the resistant genotype and corresponded with the disease phenotype. In the resistant genotype phenols were differentially expressed in a time-dependent manner with preformed soluble and cell wall-bound phenolics at earlier time points and de novo formation of lignin and lignin-like polymers at later stages of infection. This is the first study identifying a crucial role of phenol metabolism in internal defense of $B$. napus against $V$. longisporum and locating the crucial defense responses in the plant hypocotyl.
\end{abstract}

Verticillium longisporum (ex. V. dahliae var. longisporum Stark; comb. nov. Karapapa) is a soilborne fungal pathogen causing vascular diseases of cruciferous plants $(26,49-51)$. Verticillium wilt is a novel disease on oilseed rape (Brassica napus L. sp. oleifera), threatening its production particularly in the northern European countries (14).

Like the closely related species $V$. dahliae, $V$. longisporum produces durable microsclerotia which accumulate in the soil and from which plant roots are attacked (37). After germination of these resting structures, which is triggered by root exudates, fungal hyphae grow toward the root surface and penetrate the root epidermal cells near the root tips $(16,53)$. Before entering into the xylem, the fungus traverses the root cortex inter- as well as intracellularly. During most of its life cycle, V. longisporum is confined to the vascular system, a nutrient-poor environment to which the fungus is well adapted $(30,44)$. The pathogen spreads with growing hyphae and/or conidiospores conveyed with the transpiration stream into upper parts of the plant vascular system. As the host tissue turns to senescence, the pathogen enters a final saprophytic growth stage in which microsclerotia are abundantly formed in the dying stem parenchyma.

The fact that Verticillium in oilseed rape cannot be controlled efficiently with fungicides as well as the extended survival of microsclerotia in the soil (22) limits control measures of the disease on either cultural practices such as wider crop rotations or

Corresponding author: A. von Tiedemann; E-mail address: atiedem@gwdg.de

doi:10.1094/PHYTO-99-7-0802

(c) 2009 The American Phytopathological Society the use of resistant cultivars. Until recently, breeding for resistance has been hampered by the lack of sufficient resistance in commercially available breeding material. However, a promising level of resistance to $V$. longisporum has been identified in cabbage (B. oleracea; 11,20,35). More recently, significant improvement of resistance in $B$. napus against $V$. longisporum has been achieved by hybridization of resistant $B$. oleracea with $B$. rapa (36).

Resistance to wilt pathogens such as Verticillium is supposed to depend predominantly on the physical restriction and chemical inhibition of the pathogen during the systemic phase of colonization (28). Unlike many biotrophic and some necrotrophic interactions, complete resistance to vascular infection has been considered to be unlikely (2). Thus, host plants may lack severe symptoms although being systemically colonized which would normally be denoted "tolerant" instead of "resistant" $(5,19,31)$. Resistance to vascular pathogens is thus expressed "internally," representing an exceptional phenomenon in the realm of plantpathogen interactions. Usually, this type of resistance is based on the rapid build-up of mechanical barriers, vascular gels or tyloses delaying or even preventing the spread of the pathogen in the vascular system (39).

Phenolic compounds delivered along the phenylpropanoid pathway play an important role in defense to pathogen infection either as preformed or postinfectional defense factors. They have been assigned to various important biological functions in defense such as cell wall reinforcement and antimicrobial activity (43), as modulators of plant hormones in defense signaling or as scavengers of reactive oxygen species (12). Particularly the phenolic polymer lignin is an important principal structural component of secondary vascular tissue and fibers in higher plants $(23,48)$. It is 
known to play a fundamental role in mechanical support, solute conductance and disease resistance (21). Deposition of lignin, lignin-like polymers, and other wall-bound phenolic materials is reported to be a response to mechanical damage, wounding, or microbial infection (6). In addition to cell wall strengthening and increased cell wall rigidity (47), lignin deposition is supposed to decrease the diffusion of enzymes and toxins released from pathogenic fungal hyphae to the host, and of water and nutrients from the host to the fungus, thus essentially starving the intruder (46).

This study reports on histochemical and physiological data generated during the elucidation of mechanisms involved in the genotype-specific internal resistance of a B. napus genotype to $V$. longisporum. In particular, we found that resistance is related to changes in the phenolic composition of root and stem tissues, to alterations in the vascular cell walls and to vessel occlusions occurring in the vascular tissue during particular stages of infection and systemic colonization. Pathogen spread in a susceptible and a resistant $B$. napus cultivar was followed by quantitative polymerase chain reaction (qPCR). This study provides a first histological and biochemical characterization of quantitative resistance in a rapeseed genotype against $V$. longisporum.

\section{MATERIALS AND METHODS}

Fungal isolate. V. longisporum isolate VL43 from B. napus was used throughout this work. This isolate originates from oilseed rape grown in the North of Germany (49-51). Long-term storage was performed as conidial suspension with 1 to $3 \times 10^{6}$ conidia $\mathrm{ml}^{-1}$ in Czapek Dox medium supplemented with $25 \%$ glycerol at $-80^{\circ} \mathrm{C}$. Inoculum was produced by adding $500 \mu \mathrm{l}$ of the spore stock solution to $250 \mathrm{ml}$ of potato dextrose broth. The cultures were subsequently incubated for 7 days at $23^{\circ} \mathrm{C}$ on a rotary shaker at $100 \mathrm{rpm}$. The suspension was filtered through sterile gauze. Spore concentration was determined with a hemacytometer and diluted to $1 \times 10^{6}$ spores $\mathrm{ml}^{-1}$.

Plant material, inoculation procedure, and growth conditions. The susceptible winter oilseed rape commercial cultivar Falcon was provided by Norddeutsche Pflanzenzucht Hans-Georg Lembke KG (NPZ, Hohenlieth, Germany) and the resistant $B$. napus accession SEM 05-500256 was obtained from Svalöf Weibull (Svalöf, Sweden). The resistance of the latter genotype has been discovered and verified throughout a comprehensive greenhouse screening previous to this work. Seeds were double surface-disinfested by sequential immersion in $70 \%$ ethanol for 2 min and $1 \%$ sodium hypochlorite containing $0.1 \%$ Tween-20 for 15 min under constant shaking. Disinfested seeds were washed twice with autoclaved tap water and sown in double-autoclaved silica sand for germination and initial development. In all experiments described here, the inoculation of oilseed rape plantlets was performed by means of a root-dip inoculation. Plants taken for real-time PCR analysis, assessment of disease development, and histochemistry were vernalized at $4^{\circ} \mathrm{C}$ for 10 weeks and then allowed to recover for 1 week. Plants taken for analysis of phenolic compounds were grown for 14 days after germination before inoculation. Thereafter, all seedlings were carefully removed from the silica sand and the roots were washed gently under tap water. Inoculation was carried out by dipping roots in a spore suspension of $V$. longisporum isolate VL43 for $30 \mathrm{~min}$. Control plants were dipped in sterilized tap water for the same time. Plantlets taken for real-time PCR analysis and disease phenotyping (symptom development, morphological features) were then transferred into pots with a sand/soil (1:1) mixture and grown at $20^{\circ} \mathrm{C}$ and 14-h day length. Plantlets for biochemical analyses were grown in the same substrate and kept in a controlled environment chamber at $23 / 20^{\circ} \mathrm{C}$ (day/night) and 14-h day length (Philips TL5 HO lamps). Plants were watered daily and fed once a week with a full nutrient solution ('Flory Basisdünger', EUFLOR) throughout the experiments.

Assessment of disease symptoms. Disease symptoms were evaluated using an assessment key with nine classes, as described earlier (16). Healthy plants with no visible symptoms were scored 1 , diseased plants were rated from 2 to 8 according to the severity of yellowing and the occurrence of black veins, and dead plants were scored 9. Scoring was conducted at 16, 30, 51, 65, and 79 days postinoculation (dpi). Area under the disease progress curve (AUDPC) values were calculated from the disease severity values according to the following formula (8):

$$
\mathrm{AUDPC}=\sum_{i=1}^{n}\left(y_{i}+y_{i+1} / 2\right) \times\left(t_{i+1}-t_{i}\right)
$$

where $y_{i}$ is the disease severity value for observation number $i, t_{i}$ is the corresponding number of days postinoculation of an observation, and $n$ is the number of observations.

DNA isolation and real-time PCR analysis. Ten inoculated and five control plants were harvested for real-time PCR analyses at 16, 30, 51, 65, and $79 \mathrm{dpi}$. Samples, about $5 \mathrm{~cm}$ in length, were excised from the hypocotyl (below cotyledon node, herein after called 'lower stem part') and the stem part immediately above (below basal leaf, herein after called upper stem part), resulting in 20 plus 10 tissue samples and PCR analyses for the inoculated and the control variant, respectively. Roots were not included in the analysis because discrimination between fungal biomass within the roots from fungus attached to the root surface is not possible. DNA isolation and PCR analysis were performed as described previously (16). For PCR amplification and melting curve analysis, the iCycler System (Bio-Rad, Hercules, CA) was used. Primers serving for specific fragment amplification were OLG 70 (CAGCGAAACGCGATATGTAG) and OLG 71 (GGCTTGTAGGGGGTTTAGA).

Histological examinations. Sampling was conducted 21 days after inoculation on 10 inoculated and 10 healthy plants. From the hypocotyls, a piece of $2 \mathrm{~cm}$ in length was excised and preserved in a mixture of formalin, acetic acid, and ethanol (AFE; 5:5:90, $\mathrm{vol} / \mathrm{vol} / \mathrm{vol}$ ). For histochemical analyses, tissue samples were transverse cross-sectioned on a vibration microtome (Leica VT 100M, Leica, Wetzlar, Germany), treated with histochemical reagents within $5 \mathrm{~min}$, and immediately examined with light or epifluorescence microscopy (Leica DMRB, Leica, Wetzlar, Germany). Histochemical stains included toluidine blue (17), phloroglucinol$\mathrm{HCl}$ (24), and Folin-Ciocalteu reagent (38).

In order to detect vascular occlusions, transverse stem sections were treated with $0.05 \%$ toluidine blue in distilled water. After staining, vascular gels and tyloses exhibited a pink color due to the predominance of pectic components. The presence of phenolic compounds was determined with toluidine blue and the FolinCiocalteu reagent which induced a dark blue or brown to black staining, respectively. Stem sections (20 to $30 \mu \mathrm{m}$ thick) were mounted in water. Another approach to detect phenolic compounds was to harness their autofluorescence after excitation with light in the near UV range using the following filter set: 340 to $380 \mathrm{~nm}$ excitation filter, dichromatic mirror at $400 \mathrm{~nm}$ and long pass suppression filter at $425 \mathrm{~nm}$. Lignin was visualized with phloroglucinol- $\mathrm{HCl}$ (Wiesner test). Sections were immersed in phloroglucinol dissolved in $96 \%$ ethanol for $2 \mathrm{~min}$, rinsed with $32 \% \mathrm{HCl}$, and mounted in $\mathrm{HCl}(32 \%)$. After this procedure, lignin compounds stain bright pink to red.

Analysis of soluble phenolic acids, cell wall-bound phenolics, and lignin. Ten inoculated as well as control plants were harvested for biochemical analysis at weekly intervals from 7 to 28 dpi. While plants harvested at 7 and 14 dpi were separated in roots and shoots (consisting of whole plantlets except roots) due to their young developmental stage, plants at 21 and 28 dpi were divided into roots, hypocotyls, and the youngest 
fully developed leaves. Total soluble and cell wall-bound phenolic contents were determined with the Folin-Ciocalteu assay $(38,41)$.

Up to $200 \mathrm{mg}$ of plant tissue was extracted in $1.5 \mathrm{ml}$ of $80 \%$ aqueous methanol at room temperature for $1 \mathrm{~h}$ and centrifuged $(13,000 \times g)$ for $10 \mathrm{~min}$ at $4^{\circ} \mathrm{C}$. The supernatant was retained and the process was repeated once. After extraction, the supernatants were merged and used for a Folin-Ciocalteu assay, modified from Pritchard et al. (32) as follows: $100 \mu \mathrm{l}$ of extract was added to $100 \mu \mathrm{l}$ of distilled water and $200 \mu \mathrm{l}$ of Folin-Ciocalteu reagent. After incubation for $3 \mathrm{~min}$ at room temperature, $200 \mu \mathrm{l}$ of $1 \mathrm{M}$ $\mathrm{Na}_{2} \mathrm{CO}_{3}$ was added. After further incubation on a rotary shaker for $45 \mathrm{~min}$ at room temperature, the absorbance of the samples was measured at $725 \mathrm{~nm}$. Tannin was used as an external standard, and the total soluble phenolic content was reported as tannin equivalents based on a calibration curve.

For quantification of the cell wall-bound phenolic acids, a method described by Strack et al. (40) was used. After thoroughly washing the remaining pellets from the extraction of the free phenolic acids (see above), $1 \mathrm{ml}$ of $1 \mathrm{M} \mathrm{NaOH}$ was added and the samples were incubated for $1 \mathrm{~h}$ at $80^{\circ} \mathrm{C}$ and another $12 \mathrm{~h}$ at room temperature (alkaline hydrolysis). Subsequently, the samples were acidified to $\mathrm{pH}<4.0$ with $100 \mu \mathrm{l}$ of $86 \% \mathrm{H}_{3} \mathrm{PO}_{4}$. Ethyl acetate $(500 \mu \mathrm{l})$ was added and after incubating on a rotary shaker for $30 \mathrm{~min}$, the samples were centrifuged $(13,000 \times g)$ for $5 \mathrm{~min}$. After collecting the upper phase, the lower phase was extracted again with ethyl acetate. The combined ethyl acetate phases were then evaporated until dryness. The residue pellets obtained were resuspended in $500 \mu \mathrm{l}$ of methanol and used for quantitative analysis as described above.

For lignin analysis, the thioglycolic acid procedure was applied according to Bruce and West (7), modified by Otter (29). Thus, after washing, the pellet of the alkaline hydrolysis was treated with $1.5 \mathrm{ml}$ of $2 \mathrm{M} \mathrm{HCl}$ and $0.3 \mathrm{ml}$ of thioglycolic acid for $4 \mathrm{~h}$ at $94^{\circ} \mathrm{C}$. After short cooling, the pellets were collected by centrifugation, washed two times in distilled water and the residues were incubated with $1 \mathrm{ml}$ of $0.5 \mathrm{M} \mathrm{NaOH}$ for $12 \mathrm{~h}$. Subsequently, the suspension was centrifuged, extracted again with $0.5 \mathrm{ml}$ of $0.5 \mathrm{M} \mathrm{NaOH}$, and centrifuged again. The corresponding supernatants were merged and acidified with $300 \mu \mathrm{l}$ of $32 \% \mathrm{HCl}$ to precipitate the ligno-thioglycolic acid complex. After incubation for $4 \mathrm{~h}$ at $4{ }^{\circ} \mathrm{C}$ on a rotary shaker, the precipitates were collected by centrifugation and the pellets were resuspended in $2 \mathrm{ml}$ of $0.5 \mathrm{M} \mathrm{NaOH}$. Finally, the absorbance of the samples was measured at $280 \mathrm{~nm}$ after adequate dilution with $0.5 \mathrm{M} \mathrm{NaOH}$. The quantification was carried out by means of a calibration curve of alkaline lignin.

Statistical analysis. Experiments were set up in a factorial design and repeated at least two times. Results are given as the means \pm standard deviation of 10 replicates. Statistical analyses were conducted using the computer software StatGraphics (Statpoint Technologies Inc., VA). Differences among means were tested with Fisher's least significant difference test and significances were determined at $P \leq 0.05$. A general linear model procedure was used to identify significant differences among the amounts of phenolic compounds.

\section{RESULTS}

Progression of disease. Sixteen days after inoculation, infected plants of the susceptible cultivar Falcon showed first disease symptoms, namely yellowing and the occurrence of black veins on the oldest leaves, whereas no visible symptoms appeared on leaves of accession SEM 05-500256. While at 30 dpi only a few plants of SEM 05-500256 showed faint symptoms on the first true leaves, cultivar Falcon exhibited severe symptoms with $90 \%$ of the plants having $50 \%$ or more damaged leaves. Until $79 \mathrm{dpi}$, the disease progressed in 'Falcon' resulting in severe disease symptoms in all plants at the end of the experiment. In contrast, SEM 05-500256 plants looked similar to the noninoculated control plants showing only weak symptoms (yellowing) on the oldest leaves. Only at $51 \mathrm{dpi}$, disease rate of inoculated plants significantly differed from that of noninoculated controls (Table 1).

Real-time PCR analysis. At $16 \mathrm{dpi}$, V. longisporum was restricted to the plant hypocotyls in both 'Falcon' and SEM 05500256, in about equal amounts. At 30 dpi, Verticillium DNA was only detectable in the upper plant parts of the susceptible cultivar in substantial amounts (Fig. 1). The amount of $V$. longisporum DNA further rose in 'Falcon' in both plant parts with a transient decline at 65 dpi in the hypocotyl. At 79 dpi, there was twice as much Verticillium DNA in the upper stem parts $(203.45 \mathrm{ng} / \mathrm{g}$ fresh weight $[\mathrm{FW}])$ than in tissues from the plant base $(120.35 \mathrm{ng} / \mathrm{g}$ FW). By contrast, the amount of Verticillium in stems of SEM 05-500256 was substantially lower than in the susceptible cultivar and never exceeded $25.0 \mathrm{ng} / \mathrm{g} \mathrm{FW}$ in the hypocotyl or about $5.0 \mathrm{ng} / \mathrm{g} \mathrm{FW}$ in the upper stem.

Histological features of tissue from healthy and Verticilliuminfected B. napus plants. There were no differences in the histology of healthy susceptible and resistant plant hypocotyls with regard to the staining of cell walls after treatment of sections with toluidine blue (Fig. 2A and C), Folin-Ciocalteu (Fig. 2E and G) reagent, or after observation under fluorescent light (Fig. 3D and F), the latter revealing a general background autofluorescence of healthy hypocotyl tissue. However, after treatment with phloroglucinol- $\mathrm{HCl}$, hypocotyl sections from resistant control plants exhibited a stronger staining of xylem vessel walls and parenchyma cell walls than those from susceptible control plants (Fig. $3 \mathrm{~A}$ and $\mathrm{C}$ ).

Twenty-one days after inoculation, anatomical changes associated with the infection by $V$. longisporum were visible in the hypocotyl (Figs. 2 and 3). After treatment with toluidine blue, occlusions were noticeable in the xylem vessels of both B. napus varieties; however, the resistant SEM 05-500256 (Fig. 2D, arrowheads) featured a higher number of occluded vessels than the susceptible 'Falcon' (Fig. 2B, arrowheads). The majority of these obstructions appeared in vessels located near the center of the hypocotyl transverse sections. Furthermore, most of the vascular occlusions stained pink with toluidine blue indicating that they originated from primary cell wall material (18). Some of the vessel plugs exhibited a faint blue color indicating the infusion of phenolic compounds (data not shown). Toluidine blue treatment also revealed structurally unmodified parenchyma cells adjacent to xylem vessels which were filled with material stained dark-

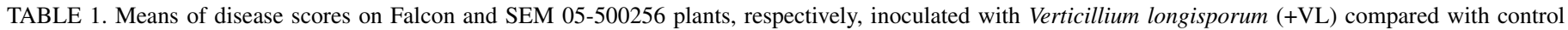
plants treated with water ${ }^{\mathrm{z}}$

Days postinoculation

\begin{tabular}{|c|c|c|c|c|c|}
\hline Variant & 16 & 30 & 51 & 65 & 79 \\
\hline Falcon control & $1.00( \pm 0.00) \mathrm{a}$ & $1.00( \pm 0.00) \mathrm{a}$ & $1.00( \pm 0.00) \mathrm{a}$ & $1.00( \pm 0.00) \mathrm{a}$ & $1.00( \pm 0.00) \mathrm{a}$ \\
\hline Falcon + VL & $2.20( \pm 0.63) \mathrm{b}$ & $4.60( \pm 1.35) b$ & $3.90( \pm 0.74) b$ & $3.80( \pm 2.10) b$ & $4.80( \pm 2.10) b$ \\
\hline SEM 500-256 control & $1.00( \pm 0.00) \mathrm{a}$ & $1.00( \pm 0.00) \mathrm{a}$ & $1.00( \pm 0.00) \mathrm{a}$ & $1.00( \pm 0.00) \mathrm{a}$ & $1.00( \pm 0.00) \mathrm{a}$ \\
\hline SEM 500-256 + VL & $1.00( \pm 0.00) \mathrm{a}$ & $1.40( \pm 0.52) \mathrm{a}$ & $1.80( \pm 0.63) \mathrm{b}$ & $1.50( \pm 0.53) \mathrm{a}$ & $1.50( \pm 0.53) \mathrm{a}$ \\
\hline
\end{tabular}

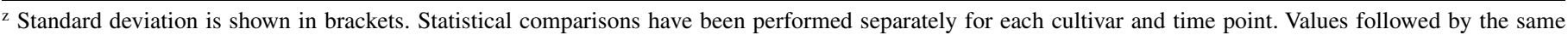
letter do not differ at $P \leq 0.05$ (least significant difference). 
blue or black (Fig. 2B and D; arrows). Staining cross-sections with Folin-Ciocalteu reagent likewise showed that xylem parenchyma cells in close proximity to xylem vessels exhibited a dark discoloration after inoculation with $V$. longisporum, indicating the presence of phenolic compounds (Fig. 2F and $\mathrm{H}$, arrows). Although for both genotypes the occurrence of these so-called phenolic-storing cells (3) was observed, their distribution in the resistant and susceptible host tissues differed, as did the way that the phenolic compounds accumulated in those cells. While in the susceptible cultivar, phenolic-storing cells only occurred around vessels located in the hypocotyl center (Fig. 2F), the resistant variety showed dark-stained paravascular contact cells all over the cross section (Fig. 2H). Furthermore, xylem vessels of the resistant genotype were surrounded by sheath cells with more pronounced and stronger staining than in susceptible plants where phenolics appeared less concentrated around vessels and more diffusively scattered (Fig. 2F compared with Fig. 2H).

The use of the Wiesner test for lignin revealed red-stained xylem vessel walls as well as parenchyma cell walls (Fig. 3A to D). After inoculation, both genotypes exhibited a stronger staining of vessel walls and walls of adjacent cells compared with other parenchyma cells (Fig. 3B and D). Thus, lignification predominantly occurred in the vascular tissue. However, vessel elements of the susceptible genotype (Fig. 3B) stained more weakly for lignin than did the corresponding cells from the resistant accession (Fig. 3D). Xylem vessels of both infected susceptible and resistant plants were plugged by pectic and lignin-like material. However, in susceptible 'Falcon' plants, vessel plugs mainly occurred in the center of the hypocotyl cross-sections (data not shown).

Observations on semi-thin sections under near UV illumination (Fig. 3E to $\mathrm{H}$ ) revealed autofluorescence to be stronger in lignified xylem areas of infected plants (Fig. $3 \mathrm{~F}$ and $\mathrm{H}$ ) in comparison to healthy plants (Fig. 3E and G). This reaction occurred at a significantly higher intensity in the resistant plants (Fig. 3G and $\mathrm{H})$. The enhanced autofluorescence further confirming the presence of phenolic compounds was observed both in the material filling the vessel elements and the cell walls of xylem and paravascular contact cells.

Soluble phenolic acids, cell wall-bound phenolic acids, and lignin. In this study, the phenolic fractions analyzed were soluble phenolic acids (Table 2), cell wall-bound phenolic acids (Table 3), and lignin (Table 4), the latter accounting for the major part of the phenolic fraction. The quantitative analysis of these compounds revealed that the resistant compared with the susceptible oilseed rape genotype in general exhibited higher constitutive and induced levels of phenols, with emphasis on the roots and shoots at early time points ( 7 and $14 \mathrm{dpi}$ ) and on roots and hypocotyls at 21 dpi.

Similarly to the single phenolic compounds analyzed, the cumulative quantitative analysis of the three phenolic fractions (Fig. 4) revealed that the resistant oilseed rape genotype exhibited higher constitutive levels of total phenols in the root and hypocotyl tissues, compared with the susceptible genotype, particularly at early time points ( 7 and $14 \mathrm{dpi}$ ). However, this was not consistently true for shoots (e.g., 7 dpi) and leaves (e.g., 21 and 28 dpi). After inoculation, genotype SEM 05-500256 featured significantly higher amounts of total phenols in all tissues in comparison to the corresponding controls and the corresponding infected susceptible 'Falcon' plants. In contrast, the susceptible genotype, upon inoculation, showed decreased total amounts of phenolics in the roots at later time points, i.e., at 21 and 28 dpi. Changes due to infection were most pronounced in the hypocotyl tissue at $21 \mathrm{dpi}$, which was in agreement with the histochemical findings. Lignin contents in cell walls of the hypocotyl tissue were increased due to infection by about $30 \%$ in the susceptible and $70 \%$ in the resistant genotype (Fig. 4).

\section{DISCUSSION}

Successful defense to vascular diseases depends on the plant's capability to react by a cascade of temporally and spatially welltuned defense responses during the systemic invasion and colonization by the pathogen (19). The aim of this study was to follow the colonization by $V$. longisporum in a resistant compared with a susceptible genotype of $B$. napus and to characterize plant resistance responses of the two contrasting genotypes biochemically and also histochemically.

Fungal biomass of $V$. longisporum in infected plants is very low. Preliminary investigations using the classical techniques such as plating xylem sap and vascular tissue from infected plants on agar revealed that these methods detected $V$. longisporum at much lower frequencies than qPCR (data not shown). Moreover, realtime PCR allows for an accurate quantification of the pathogen in the plant matrix, which is not feasible with classical plating techniques. Thus, precise studies on the systemic spread of this vascu-

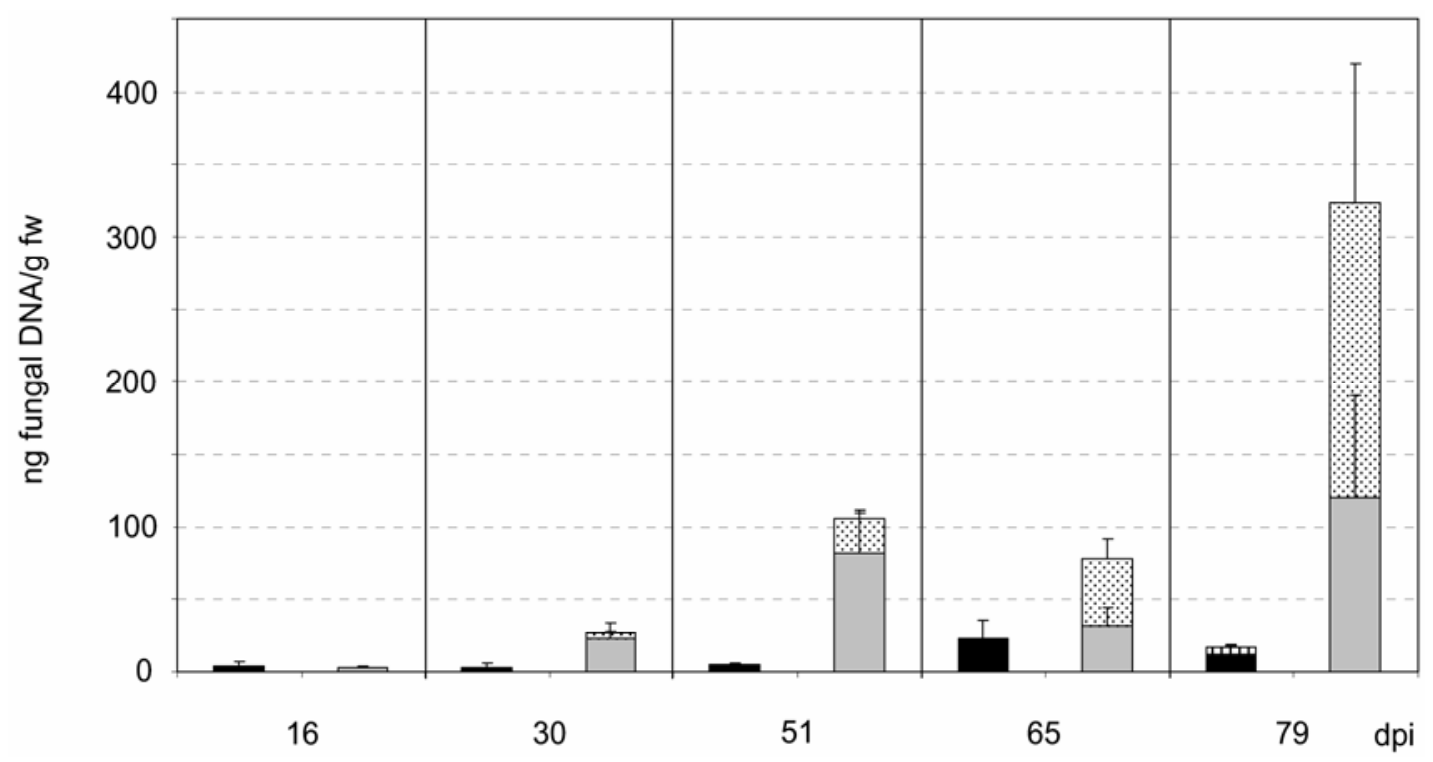

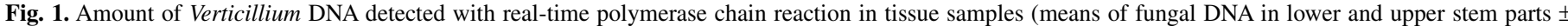

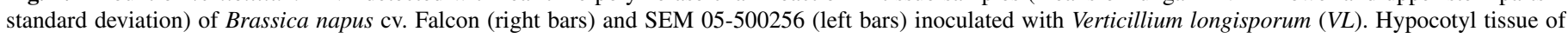
SEM 05-500256, black bars; upper stem part of SEM 05-500256, dashed bars; hypocotyl tissue of Falcon, gray bars; and upper stem part of Falcon, dotted bars. 

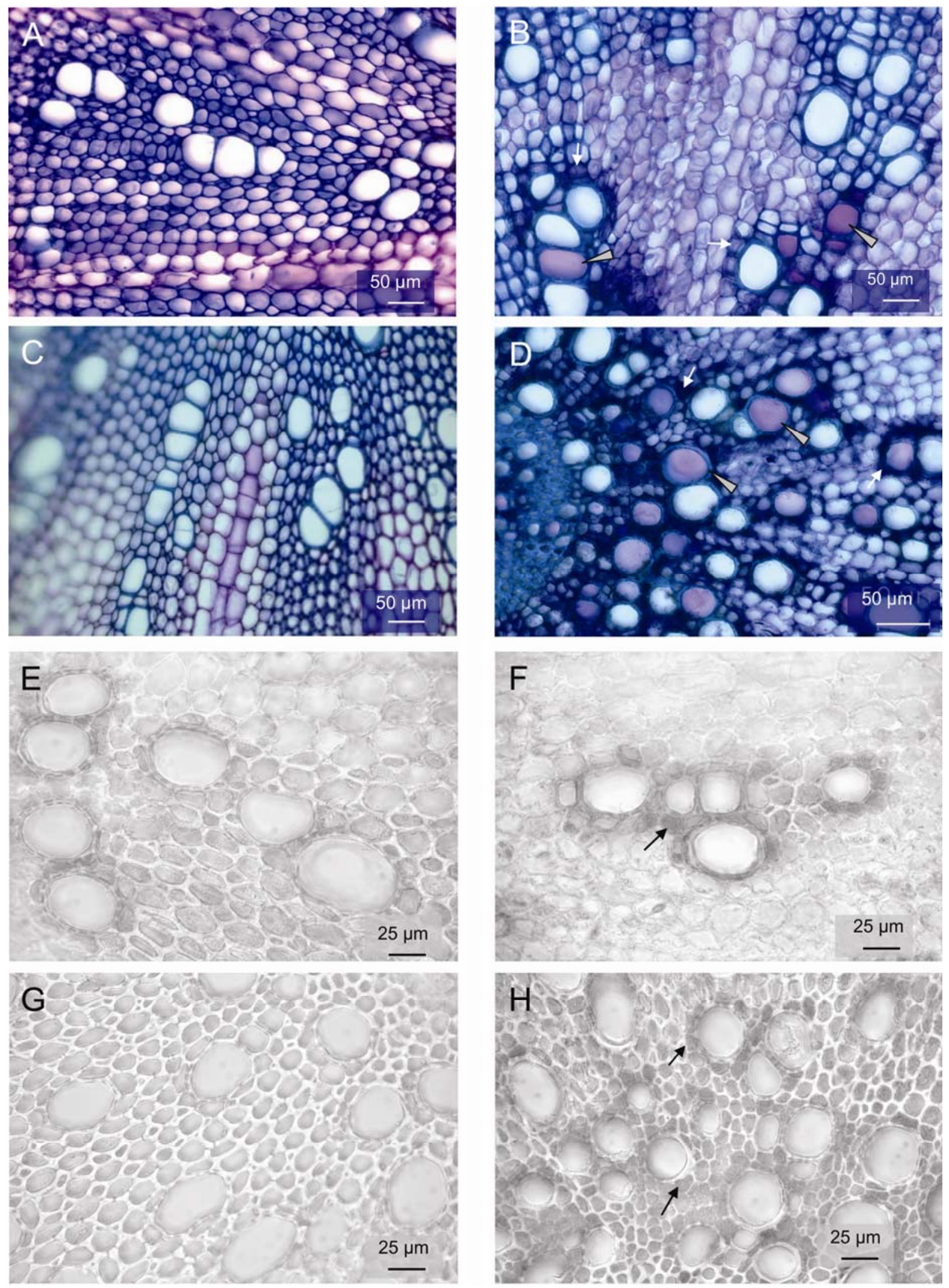

Fig. 2. A to D, Light microscopy image of hypocotyl cross sections of susceptible cultivar Falcon and resistant accession SEM 05-500256 stained with toluidine blue for detection of occlusions and polyphenolic substances in plants infected with Verticillium longisporum and control plants (21 days postinoculation [dpi]). A, Falcon, noninfected control; xylem vessels completely lacking obstructions. B, 'Falcon', infected; dark discoloration (arrow) indicates a pronounced accumulation of polyphenolic material in xylem parenchyma cells. Arrowheads highlight obstructed vessels. C, SEM 05-500256, control plants; vessels and adjacent xylem parenchyma are completely free and clear. D, SEM 05-500256, infected; the pronounced dark discoloration of cells directly neighboring the xylem vessels indicates massive accumulation of polyphenols (phenol-storing cells). E to $\mathbf{H}$, Light microscopy image of hypocotyl cross sections of cultivar Falcon and accession SEM 05-500256 stained with Folin-Ciocalteu reagent for detection of accumulating polyphenolic substances in control and infected plants (21 dpi). E, 'Falcon', control. F, 'Falcon', infected; accumulation of polyphenolic substances in cells of xylem parenchyma (arrow). G, SEM 05-500256, control. H, SEM 05500256, infected; strong accumulation of phenolic substances restricted to phenol-storing cells directly neighboring xylem vessels (arrows). 

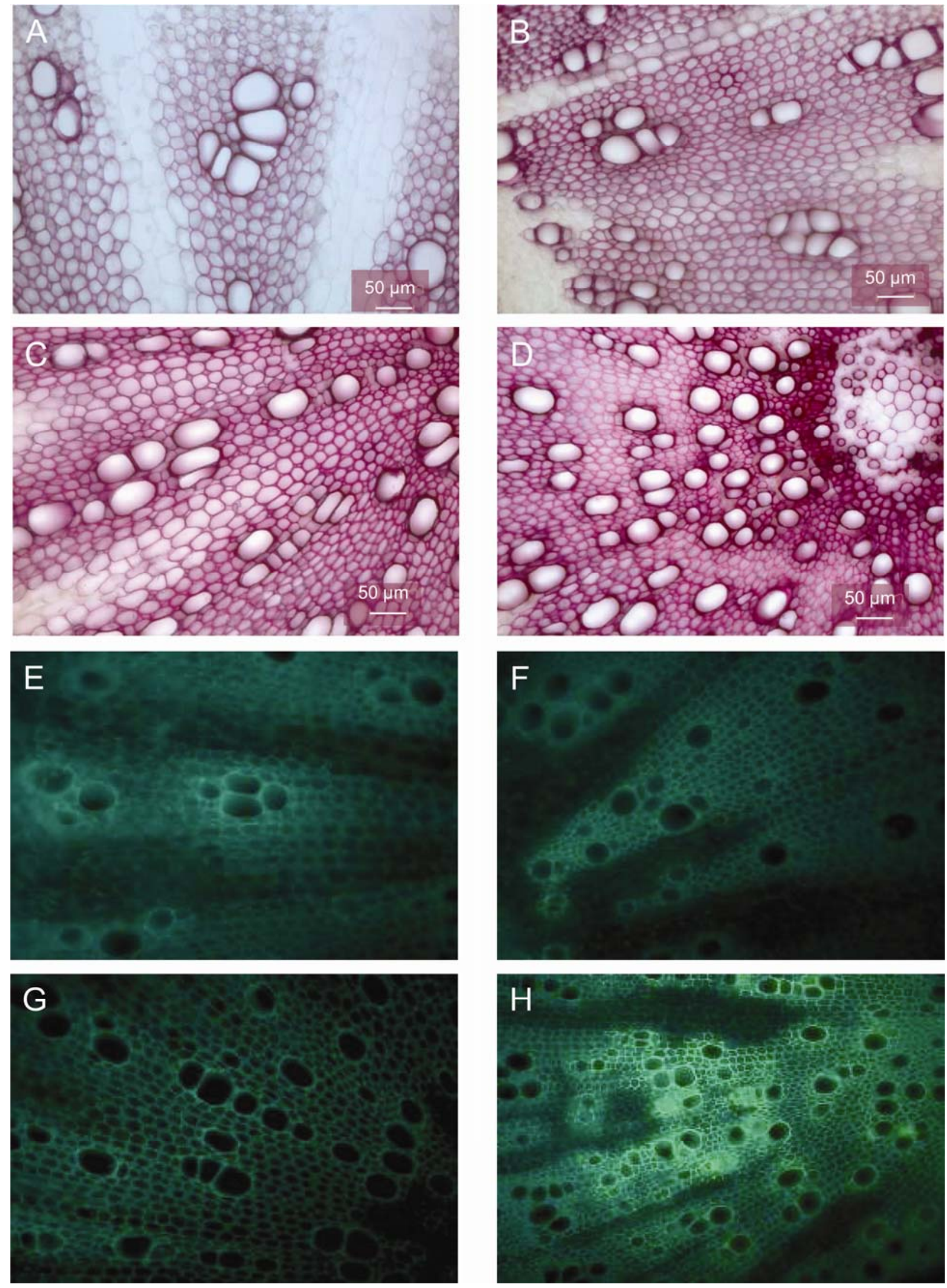

Fig. 3. A to D, Light microscopy image of hypocotyl cross sections of cultivar Falcon and accession SEM 05-500256 after staining with phloroglucinol-HCl for detection of lignin in control plants and after infection by Verticillium longisporum (21 days postinoculation [dpi]). A, Falcon, noninfected control. B. Falcon, infected; sparse lignification of vessel elements and adjacent xylem parenchyma cells. C, SEM 05-500256, control. D, SEM 05-500256, infected; increased lignification particularly of xylem vessels and adjacent parenchyma cells. E to $\mathbf{H}$, Epifluorescence microscopy image of hypocotyl cross sections of cultivar Falcon and accession SEM 05-500256; documentation of autofluorescence in the near UV-range typical for polyphenols in control plants and plants infected with V. longisporum (21 dpi). E, Falcon, control. F, Falcon, infected. G, SEM 05-500256, control. H, SEM 05-500256, infected. The resistant genotype SEM 05500256 exhibits a much stronger reaction than the susceptible cultivar Falcon. E to H, 200× magnification. 
lar pathogen have only become possible by the availability of qPCR techniques. In our studies, real-time PCR analysis revealed successful root penetration and invasion of lower plant parts in both genotypes, however, significant differences were found in the further spread into the shoots. While in the susceptible 'Falcon' the fungus spread readily into upper parts until $79 \mathrm{dpi}$, colonization of the resistant genotype SEM 05-500256 was confined to the plant base. This finding indicates that resistance to $V$. longisporum is internally expressed during stages later than root penetration and primary invasion of the root vascular system and confirms recent observations on oilseed rape roots being even susceptible to penetration, but not systemically colonized, by a nonpathogenic Verticillium species, V. dahliae (16). Moreover, the qPCR data provide evidence that the hypocotyl tissue plays a crucial role in expression of resistance to $V$. longisporum. A similar pattern of restricted systemic growth has been reported from cotton infected with $V$. dahliae (2).
In this work, we therefore placed emphasis on the hypocotyl tissue and studied the formation of mechanical barriers and accumulation of soluble and wall-bound phenolics as well as lignin in response to infection with $V$. longisporum. The primary observation was that responses observed in the susceptible and the resistant genotypes were similar by nature but differed significantly in their intensity.

Formation of occlusions in plant vessels by gums, gels, and/or tyloses is a common phenomenon in resistance to vascular wilt diseases (42). Particularly the occurrence of vascular gels has been extensively studied in the past and several possible explanations for their origin have been offered. The most recent hypothesis is that in the event of pits being too small to allow the formation of tyloses, synthesis of wall material is induced during pathogenesis, with the result of wall material being extruded to form gels in the vessel lumen. Thus, gel plugs may occur together with tyloses in the same plant as a response to vascular infection

TABLE 2. Content of soluble phenolic acids in healthy and infected tissue extracts of cultivar Falcon and genotype SEM 05-500256 as measured by the FolinCiocalteu assay ${ }^{\mathrm{z}}$

\begin{tabular}{llcccc}
\hline $\begin{array}{l}\text { Days post- } \\
\text { inoculation }\end{array}$ & Tissue & Falcon control & $\begin{array}{c}\text { Falcon }+ \\
\text { Verticillium longisporum }\end{array}$ & SEM 05-500256 control & $\begin{array}{c}\text { SEM 05-500256 }+ \\
\text { Verticillium longisporum }\end{array}$ \\
\hline 7 & Root & $02.36( \pm 0.56) \mathrm{a}$ & $02.12( \pm 0.54) \mathrm{a}$ & $02.94( \pm 0.66) \mathrm{b}$ & $03.67( \pm 0.80) \mathrm{c}$ \\
& Shoot & $09.19( \pm 0.60) \mathrm{b}$ & $07.26( \pm 0.84) \mathrm{b}$ & $10.06( \pm 1.10) \mathrm{c}$ & $10.54( \pm 0.81) \mathrm{c}$ \\
14 & Root & $03.62( \pm 0.40) \mathrm{a}$ & $03.77( \pm 0.57) \mathrm{a}$ & $04.80( \pm 0.51) \mathrm{b}$ & $06.05( \pm 0.56) \mathrm{c}$ \\
& Shoot & $06.64( \pm 0.37) \mathrm{a}$ & $08.22( \pm 0.81) \mathrm{b}$ & $09.79( \pm 0.62) \mathrm{c}$ & $11.10( \pm 0.45) \mathrm{d}$ \\
& Root & $04.19( \pm 0.45) \mathrm{a}$ & $04.00( \pm 0.31) \mathrm{a}$ & $04.42( \pm 0.66) \mathrm{a}$ & $05.32( \pm 0.57) \mathrm{b}$ \\
& Hypocotyl & $02.94( \pm 0.56) \mathrm{a}$ & $03.76( \pm 0.25) \mathrm{b}$ & $03.11( \pm 0.16) \mathrm{a}$ & $04.71( \pm 0.34) \mathrm{c}$ \\
& Leaf & $10.91( \pm 1.81) \mathrm{a}$ & $11.15( \pm 2.02) \mathrm{a}$ & $09.55( \pm 0.74) \mathrm{a}$ & $13.49( \pm 1.24) \mathrm{b}$ \\
& Root & $03.27( \pm 0.33) \mathrm{b}$ & $02.71( \pm 0.19) \mathrm{a}$ & $03.84( \pm 0.25) \mathrm{c}$ & $04.84( \pm 0.42) \mathrm{d}$ \\
& Hypocotyl & $02.36( \pm 0.06) \mathrm{a}$ & $02.93( \pm 0.12) \mathrm{b}$ & $02.29( \pm 0.11) \mathrm{a}$ & $03.14( \pm 0.20) \mathrm{c}$ \\
\hline
\end{tabular}

${ }^{\mathrm{z}}$ Total free phenolic content is given in tannin equivalents $(\mathrm{mg} / \mathrm{g}$ dry weight) as mean ( \pm standard deviation) of 10 samples per group. Comparison of means performed separately for each tissue type and time point. Thus, values within the same row followed by the same letter are not significantly different at $P \leq 0.05$ (least significant difference).

TABLE 3. Content of cell wall-bound phenolic acids in healthy and infected tissue extracts of cultivar Falcon and genotype SEM 05-500256 as measured by the Folin-Ciocalteu assay ${ }^{2}$

\begin{tabular}{|c|c|c|c|c|c|}
\hline $\begin{array}{l}\text { Days post- } \\
\text { inoculation }\end{array}$ & Tissue & Falcon control & $\begin{array}{c}\text { Falcon }+ \\
\text { Verticillium longisporum } \\
\end{array}$ & SEM 05-500256 control & $\begin{array}{c}\text { SEM 05-500256 + } \\
\text { Verticillium longisporum } \\
\end{array}$ \\
\hline \multirow[t]{2}{*}{7} & Root & $0.34( \pm 0.09) \mathrm{b}$ & $0.23( \pm 0.08) \mathrm{a}$ & $0.44( \pm 0.08) \mathrm{c}$ & $0.50( \pm 0.11) \mathrm{c}$ \\
\hline & Shoot & $0.23( \pm 0.02) \mathrm{c}$ & $0.18( \pm 0.02) \mathrm{a}$ & $0.22( \pm 0.03) b c$ & $0.20( \pm 0.02) \mathrm{ab}$ \\
\hline 14 & Shoot & $0.14( \pm 0.04) \mathrm{a}$ & $0.14( \pm 0.03) \mathrm{a}$ & $0.13( \pm 0.01) \mathrm{a}$ & $0.21( \pm 0.02) \mathrm{b}$ \\
\hline \multirow[t]{3}{*}{21} & Root & $0.75( \pm 0.08) \mathrm{c}$ & $0.55( \pm 0.06) \mathrm{a}$ & $0.68( \pm 0.09) \mathrm{b}$ & $0.87( \pm 0.07) \mathrm{d}$ \\
\hline & Hypocotyl & $0.45( \pm 0.10)$ a & $0.57( \pm 0.09)$ a & $0.56( \pm 0.06) b$ & $0.87( \pm 0.06) \mathrm{c}$ \\
\hline & Leaf & $0.13( \pm 0.02) \mathrm{a}$ & $0.17( \pm 0.04) \mathrm{b}$ & $0.12( \pm 0.02) \mathrm{a}$ & $0.17( \pm 0.02) \mathrm{b}$ \\
\hline 28 & Leaf & $0.13( \pm 0.03) \mathrm{c}$ & $0.11( \pm 0.02) \mathrm{ab}$ & $0.10( \pm 0.02) \mathrm{a}$ & $0.12( \pm 0.02) b c$ \\
\hline
\end{tabular}

${ }^{\mathrm{z}}$ Total ester-bound phenolic content is given in tannin equivalents (mg/g dry weight) as mean ( \pm standard deviation) of 10 samples per group. Comparison of means performed separately for each tissue type and time point. Thus, values within the same row followed by the same letter are not significantly different at $P \leq 0.05$ (least significant difference).

TABLE 4. Lignin content in healthy and infected tissue extracts of cultivar Falcon and genotype SEM 05-500256 measured as ligninthioglycolic acid (mg/g dw)

\begin{tabular}{llcccc}
\hline $\begin{array}{l}\text { Days post- } \\
\text { inoculation }\end{array}$ & Tissue & Falcon control & $\begin{array}{c}\text { Falcon }+ \\
\text { Verticillium longisporum }\end{array}$ & SEM 05-500256 control & $\begin{array}{c}\text { SEM 05-500256 }+ \\
\text { Verticillium longisporum }\end{array}$ \\
\hline 7 & Root & $22.81( \pm 05.48) \mathrm{a}$ & $22.36( \pm 06.00) \mathrm{a}$ & $28.88( \pm 03.45) \mathrm{b}$ & $31.46( \pm 05.13) \mathrm{b}$ \\
& Shoot & $04.85( \pm 00.61) \mathrm{c}$ & $04.20( \pm 00.50) \mathrm{b}$ & $03.52( \pm 00.20) \mathrm{a}$ & $04.75( \pm 00.54) \mathrm{c}$ \\
14 & Root & $34.73( \pm 03.00) \mathrm{a}$ & $41.17( \pm 05.67) \mathrm{b}$ & $75.21( \pm 11.12) \mathrm{d}$ & $67.96( \pm 05.29) \mathrm{c}$ \\
& Shoot & $05.91( \pm 00.69) \mathrm{a}$ & $05.51( \pm 01.44) \mathrm{a}$ & $09.08( \pm 01.24) \mathrm{b}$ & $10.42( \pm 01.78) \mathrm{c}$ \\
21 & Root & $59.28( \pm 14.04) \mathrm{a}$ & $49.86( \pm 04.23) \mathrm{a}$ & $70.17( \pm 15.43) \mathrm{b}$ & $79.84( \pm 08.97) \mathrm{b}$ \\
& Hypocotyl & $36.61( \pm 07.29) \mathrm{a}$ & $48.29( \pm 07.82) \mathrm{b}$ & $55.95( \pm 06.07) \mathrm{b}$ & $95.89( \pm 12.67) \mathrm{c}$ \\
28 & Leaf & $01.60( \pm 00.33) \mathrm{a}$ & $01.50( \pm 00.38) \mathrm{a}$ & $01.86( \pm 00.48) \mathrm{a}$ & $02.38( \pm 00.56) \mathrm{b}$ \\
& Root & $56.89( \pm 07.78) \mathrm{b}$ & $39.74( \pm 04.37) \mathrm{a}$ & $73.55( \pm 16.17) \mathrm{c}$ & $92.56( \pm 10.40) \mathrm{d}$ \\
& Hypocotyl & $58.68( \pm 09.28) \mathrm{a}$ & $63.19( \pm 09.19) \mathrm{a}$ & $78.88( \pm 16.75) \mathrm{b}$ & $96.85( \pm 18.01) \mathrm{c}$ \\
& Leaf & $03.05( \pm 00.24) \mathrm{bc}$ & $02.78( \pm 00.45) \mathrm{b}$ & $01.88( \pm 00.25) \mathrm{a}$ & $02.92( \pm 00.52) \mathrm{bc}$ \\
\hline
\end{tabular}

\footnotetext{
${ }^{\mathrm{z}}$ Contents are given as mean ( \pm standard deviation) of 10 samples per group. Comparison of means performed separately for each tissue type and time point.
}

Thus, values within the same row followed by the same letter are not significantly different at $P \leq 0.05$ (least significant difference). 

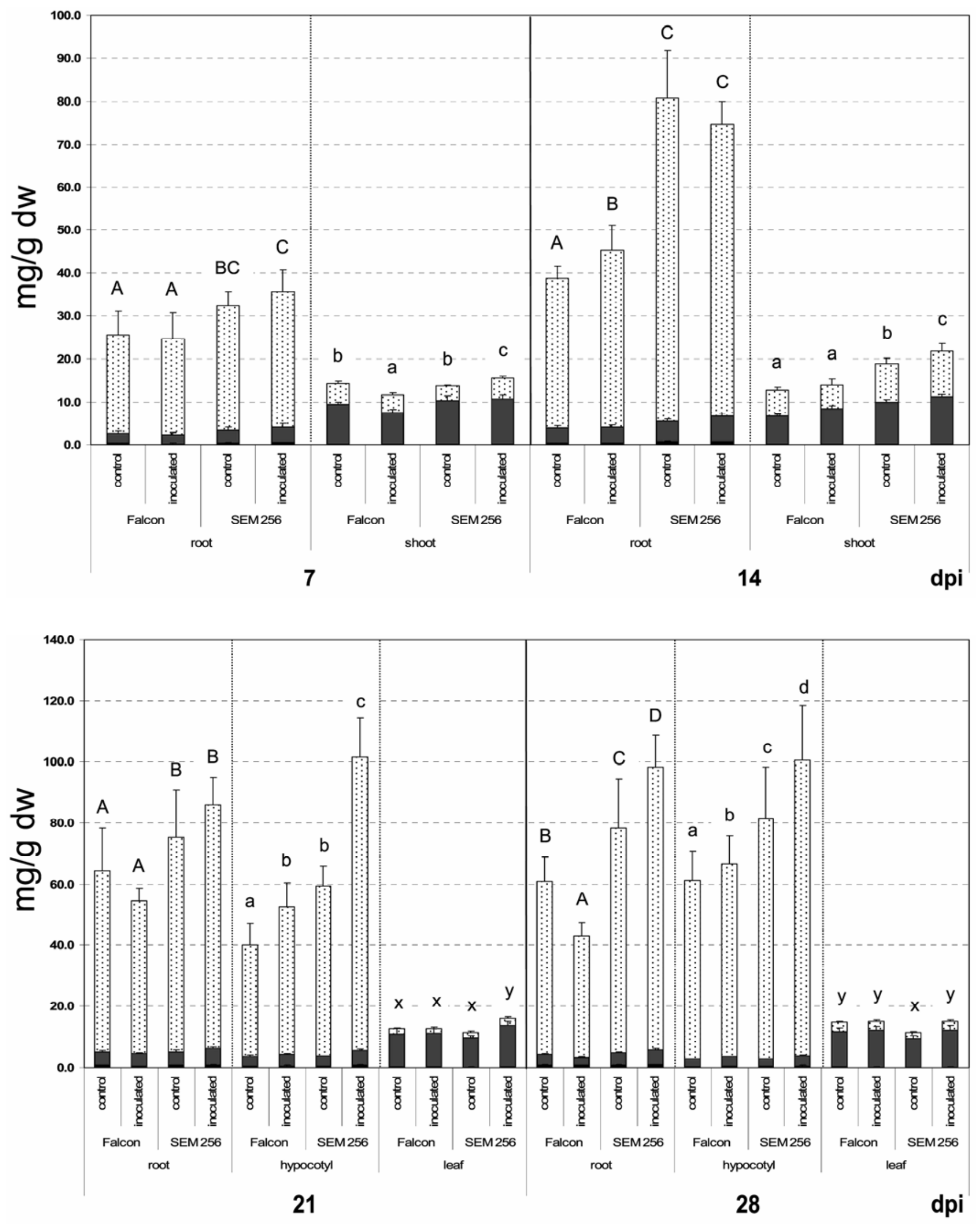

Fig. 4. Total phenolic contents, including cell wall-bound phenolic acids (black bars), soluble phenolic acids (gray bars), and lignin (dotted bars) in root and shoot tissue samples of Brassica napus, cultivar Falcon, and genotype SEM 05-500256, 7 to 28 days postinoculation (dpi) with Verticillium longisporum. Each data point is a mean ( \pm standard deviation) of 10 samples per group. Letters above columns denote significance referred to the total phenol content. Means for total phenol content were compared separately for each tissue type and time point. Thus, same letters (uppercase letters A to D for roots, lowercase letters a to d for shoots at 7 and 14 dpi and hypocotyls at 21 and 28 dpi, respectively, and lowercase letters x and y for leaves at 21 and 28 dpi) within one tissue type indicate lack of significant differences at $P \leq 0.05$ (least significant difference). Note different ranges of $x$ axes of the upper graphs (100.0) and the graphs below (140.0). 
(31). The efficiency of such mechanical restrictions of pathogen growth has been concluded from an inverse correlation between the extent of occlusion formation and the degree of colonization by the pathogen and symptom expression $(5,42)$. Likewise, we observed a positive relationship between the abundance of vascular occlusions and the level of resistance in oilseed rape. Furthermore, the histochemical staining of vascular obstructions in infected $B$. napus stem tissues with toluidine blue and phloroglucinol- $\mathrm{HCl}$ indicates a phenolic and lignin-like infusion of these occlusions.

Hitherto, obstructions of vessels induced by either $V$. dahliae or $V$. albo-atrum generally lead to water stress and wilt symptoms (34). By contrast, infection of B. napus with $V$. longisporum does not result in a wilt (14). This may have several reasons. First, in contrast to $V$. dahliae $(25,52)$ and $V$. albo-atrum (15), no wilt toxins of $V$. longisporum have been identified so far. Second, even massive inoculation of a susceptible genotype with $V$. longisporum resulted in only partial colonization of individual xylem vessels by the fungus (16). This may enable the plant to compensate for individual occluded vessels by the formation of new xylem elements as has been reported for hop and tomato plants infected with V. albo-atrum (42). To what extent this potential for compensation bears a meaning in a field situation with high disease pressure and coincident drought stress remains to be investigated.

During the formation of vascular occlusions, so-called phenolic-storing cells play an important role. These are specialized cells in which phenolics are synthesized and stored in the vacuole during cell differentiation (3). In several investigations on phenolic-storing cells of various higher plants vacuolar phenolics in a reduced state have been reported (4). The histochemical analyses in the present study suggest that this may also be true for $B$. napus. We assume that these stored phenolics might be released in infected vascular tissue and diffuse from their vacuolar compartments into the cell at large. Here they may be oxidized and polymerized to form polyphenols, thereby also regulating the cellular redox status in the plant as response to stress (9). In addition, oxidized phenols may form lignin and seal off infections at the site of penetration. Finally, if this defense fails and the stress persists, levels of auxin and ethylene may increase that cause a cascade of secondary metabolic and growth responses. Thus, auxin was shown to promote lateral growth in paravascular contact cells that surround the xylem vessels resulting in the formation of vascular occlusions (3), structures observed in this study as a response to Verticillium infection. However, in the current study oxidized phenolic compounds stained with toluidine blue and Folin-Ciocalteu reagent were observed both in the susceptible and the resistant genotype. Our observations in the resistant genotype, however, imply that internal resistance is at least in part based on a more localized and intense accumulation of free phenolic compounds.

Besides their role in vascular occlusions, soluble phenolic acids may directly inhibit microbial growth. Thus, De Ascensao and Dubery (10) reported a substantial increase in total soluble phenolics in banana roots early after treatment with an elicitor from F. oxysporum f. sp. cubense race 4 . In this study, both constitutive and induced levels of soluble phenolic acids in the resistant $B$. napus genotype were significantly increased in comparison to that found in susceptible 'Falcon', starting at early stages of infection (7 and $14 \mathrm{dpi}$ ). However, in a parallel study, we did not find any antifungal properties of xylem sap extracted from infected resistant or susceptible compared with healthy plants (unpublished data). This finding corroborates the significance of vascular occlusions observed in the histochemical studies as mechanical barriers erected for containment of $V$. longisporum in the basal plant parts.

Phenolic compounds have also been proposed to act as physical barriers to fungal colonization (27). The primary reinforcement of the cell wall, apart from lignification, is due to the incorporation of hydroxycinnamoyl esters (33). Our investigations show that cell wall-bound phenolic acids are likely to contribute to the resistance of $B$. napus against $V$. longisporum. Similar to soluble phenolics, the constitutive level of cell wall-bound phenolics was substantially higher in the roots of resistant SEM 05-500256 plants compared to the susceptible genotype, starting in the first 2 weeks. This was in agreement with a pronounced accumulation of cell wall-bound phenolics in the hypocotyl tissue of the resistant genotype observed at $21 \mathrm{dpi}$.

Besides the fact that a reduction in lignin content has serious physiological consequences on the vascular rigidity (1), lignin plays a pivotal role in plant defense (33). Thus, investigations on banana roots infected with $F$. oxysporum f. sp. cubense revealed that deposition of lignin plays a major role in cell wall strengthening (45). Our histochemical findings of elevated levels of phenolic and lignin-like compounds corresponded well with the biochemical analyses, revealing significantly higher constitutive amounts of lignin in roots and hypocotyls of resistant oilseed rape plants. Interestingly, particularly at $21 \mathrm{dpi}$ a strong accumulation of lignin was found in the hypocotyl of infected resistant plants, closely corresponding with the histochemical findings. This supports results from Dubery and Smit (13) who showed an increased lignification in cotton hypocotyl tissue following treatment with an elicitor from $V$. dahliae.

Altogether, our observations strongly indicate an important function of phenol metabolism in the hypocotyl tissue in restricting this vascular pathogen. In the resistant genotype SEM 05-500256, phenols are differentially expressed in a time-dependent manner. While at earlier time points preformed soluble and cell wall-bound phenolics appear to limit the extent of infection and colonization by the fungal pathogen, de novo formation of lignin and lignin-like polymers become more important at later stages of infection. Although the results of this study provide an indication of a role of phenol metabolism in the hypocotyl in resistance of $B$. napus to $V$. longisporum, it remains to be analyzed in more detail how this response is triggered and how phenolic compounds precisely contribute to the inhibition of fungal spread. In conclusion, the defense response in oilseed rape towards Verticillium involves various internally expressed protective mechanisms that contribute to the overall disease resistance. The type of resistance studied becomes effective only after root penetration and primary colonization of the plant hypocotyl. Thus, the resistant genotype exhibits an internal resistance hindering the pathogen from systemic spread into the shoot while being unable to prevent the colonization of the plant base.

\section{ACKNOWLEDGMENTS}

We thank the breeding companies represented by the GFP (Gemeinschaft zur Förderung der privaten deutschen Pflanzenzüchtung e.V.) for constant support and fruitful cooperation. The funding of this study by GFP and BMELV (German Ministry of Food, Agriculture and Consumer Protection) is acknowledged.

\section{LITERATURE CITED}

1. Anterola, A. M., and Lewis, N. G. 2002. Trends in lignin modification: A comprehensive analysis of the effects of genetic manipulations/mutations on lignification and vascular integrity. Phytochemistry 61:221-294.

2. Beckman, C. H. 1987. The Nature of Wilt Diseases of Plants. The American Phytopathological Society, St. Paul, MN.

3. Beckman, C. H. 2000. Phenolic-storing cells: Keys to programmed cell death and periderm formation in wilt disease resistance and in general defence responses in plants? Physiol. Mol. Plant Pathol. 57:101-110.

4. Beckman, C. H., Müller, W. C., and MacHardy, W. E. 1972. The localization of stored phenols in plant hairs. Physiol. Plant Pathol. 2:69-74.

5. Bishop, C. D., and Cooper, R. M. 1984. Ultrastructure of vascular colonization by fungal wilt pathogens. II. Invasion of resistant cultivars. Physiol. Plant Pathol. 24:277-289. 
6. Boudet, A. M., Lapierre, C., and Grima-Pettenati, J. 1995. Biochemistry and molecular biology of lignification. New Phytol. 129:203-236.

7. Bruce, R. J., and West, C. A. 1989. Elicitation of lignin biosynthesis and isoperoxidase activity by pectic fragments in suspension cultures of Castor bean. Plant Physiol. 91:889-897.

8. Campbell, C. L., and Madden, L. V. 1990. Introduction to Plant Disease Epidemiology. John Wiley, New York.

9. Chong, J., Baltz, R., Fritig, B., and Saindrenan, P. 1999. An early salicylic acid-, pathogen- and elicitor-inducible tobacco glucosyltransferase: Role in compartmentalization of phenolics and $\mathrm{H}_{2} \mathrm{O}_{2}$ metabolism. FEBS Letts. 458:204-208

10. De Ascensao, A. R., and Dubery, I. A. 2003. Soluble and cell wall-bound phenolics and phenolic polymers in Musa acuminata roots exposed to elicitors from Fusarium oxysporum f. sp. cubense. Phytochemistry 63:679-686.

11. Dixelius, C., Happstadius, I., and Berg, G. 2005. Verticillium wilt on Brassica oil crops - A Swedish perspective. J. Swedish Seed Assoc. 115:36-48.

12. Dixon, R. A., and Paiva, N. L. 1995. Stress-induced phenylpropanoid metabolism. Plant Cell 7:1085-1097.

13. Dubery, I. A., and Smit, F. 1994. Phenylalanine ammonia-lyase from cotton (Gossypium hirsutum) hypocotyls: Properties of the enzyme induced by a Verticillium dahliae phytotoxin. Biochim. Biophys. Acta 1207:24-30.

14. Dunker, S., Keunecke, H., Steinbach, P., and von Tiedemann, A. 2008. Impact of Verticillium longisporum on yield and morphology of winter oilseed rape (Brassica napus) in relation to systemic spread in the plant. J. Phytopathol. 156:698-707.

15. El Assami, A. 1999. Contribution to the study of the chemical composition of Verticillium albo-atrum secretions in liquid medium. Mycopathologia 144:93-95.

16. Eynck, C., Koopmann, B., Grunewaldt-Stöcker, G., Karlovsky, P., and von Tiedemann, A. 2007. Differential interactions of Verticillium longisporum and Verticillium dahliae with Brassica napus detected with molecular and histological techniques. Eur. J. Plant Pathol. 118:259-274.

17. Feder, N., and O'Brien, T. P. 1968. Plant microtechniques: Some principles and new methods. Am. J. Bot. 55:123-142.

18. Gerlach, D. 1984. Botanische Mikrotechnik. Eine Einfuehrung. 3.ed. Georg Thieme Verlag, Stuttgart, Germany.

19. Hammond-Kosack, K. E., and Jones, J. D. G. 1996. Resistance genedependent plant defense responses. Plant Cell 8:1773-1791.

20. Happstadius, I., Ljunberg, A., Kristiansson, B., and Dixelius, C. 2003. Identification of Brassica oleracea germplasm with improved resistance to Verticillium wilt. Plant Breed. 122:30-34.

21. Harakava, R. 2005. Genes encoding enzymes of the lignin biosynthesis pathway in Eucalyptus. Gen. Mol. Biol. 28:601-607.

22. Heale, J. B., and Karapapa, K. V. 1999. The Verticillium threat to Canada's major oilseed crop: Canola. Can. J. Plant Pathol. 21:1-7.

23. Humphreys, J. M., and Chapple, C. 2002. Rewriting the lignin road map. Curr. Opin. Plant Biol. 5:224-229.

24. Jensen, W. A. (ed.) 1962. Botanical Histochemistry: Principles and Practice. Freeman and Co., San Francisco, CA.

25. Jiang, J., Fan, L. W., and Wu, W. H. 2005. Evidences for involvement of endogenous cAMP in Arabidopsis defence response to Verticillium toxins. Cell Res. 15:585-592.

26. Karapapa, V. K., Bainbridge, B. W., and Heale, J. B. 1997. Morphological and molecular characterisation of Verticillium longisporum comb. nov., pathogenic to oilseed rape. Mycol. Res. 101:1281-1294.

27. Keen, N. T. 1992. The molecular biology of disease resistance. Plant Mol. Biol. 19:109-122.

28. Nicholson, R. L., and Hammerschmidt, R. 1992. Phenolic compounds and their role in disease resistance. Annu. Rev. Phytopathol. 30:369-389.

29. Otter, T. J. 1996. Untersuchungen zur Ligninbildung bei der Fichte (Picea abies [L.] Karst.). Dissertation. University of Freiburg, Germany.

30. Pegg, G. F. 1985. Life in a black hole-The micro-environment of the vascular pathogen. Trans. Br. Mycol. Soc. 85:1-20.

31. Pegg, G. F., and Brady, B. L. 2002. Resistance. Pages 193-340 in: Verticillium Wilts. CAB Publishing, Wallingford, UK.

32. Pritchard, S., Peterson, C., Runion, G. B., Prior, S., and Rogers, H. 1997.
Atmospheric $\mathrm{CO}_{2}$ concentration, $\mathrm{N}$ availability, and water status affect patterns of ergastic substance deposition in longleaf pine (Pinus palusitris Mill.) foliage. Trees Struct. Funct. 118:494-503.

33. Ride, J. P. 1983. Cell walls and other structural barriers in defense. Pages 215-236 in: Biochemical Plant Pathology. J. A. Callow, ed. Wiley Publishers, Chichester, U.K.

34. Robb, J., Busch, L. V., and Lu, B. C. 1975. Ultrastructure of wilt syndrome caused by Verticillium dahliae. II. In sunflower leaves. Can. J. Bot. 53:2725-2739.

35. Rygulla, W., Snowdon, R. J., Eynck, C., Koopmann, B., von Tiedemann, A., Lühs, W., and Friedt, W. 2007. Broadening the genetic basis of Verticillium longisporum resistance in Brassica napus by interspecific hybridisation. Plant Breed. 126:596-602.

36. Rygulla, W., Seyis, F., Lühs, W., Eynck, C., von Tiedemann, A., Friedt, W., and Snowdon, R. J. 2007. Combination of resistance to Verticillium longisporum from zero erucic acid Brassica oleracea and oilseed Brassica rapa genotypes in resynthesized rapeseed (Brassica napus) lines. Phytopathology 97:1391-1396.

37. Schnathorst, W. C. 1981. Life cycle and epidemiology of Verticillium. Pages 81-111 in: Fungal Wilt Diseases of Plants. M. E. Mace, A. A. Bell, and C. H. Beckmann, eds. Academic Press, NY.

38. Singleton, V. L., Orthofer, R., and Lamuela-Raventós, R. M. 1999 Analysis of total phenols and other oxidation substrates and antioxidants by means of Folin-Ciocalteu reagent. Methods Enzymol. 299:152-178.

39. Sinha, A. K., and Wood, R. K. S. 1968. Studies on the nature of resistance of resistance in tomato plants to Verticillium albo-atrum. Ann. Appl. Biol. 59:143-154.

40. Strack, D., Heilemann, J., Mömken, M., and Wray, V. 1988. Cell wallconjugated phenolics from coniferae leaves. Phytochemistry 27:35173521.

41. Swain, T., and Hillis, W. E. 1959. The phenolic constituents of Prunus domestica I. The quantitative analysis of phenolic constituents. J. Sci. Food Agric. 10:63-68.

42. Talboys, P. W. 1984. Damage symptoms and crop loss caused by vascular pathogens. Pages 171-187 in: Plant Diseases: Infection, Damage, and Loss. R. K. S. Wood and G. J. Jellis, eds. Blackwell Scientific Publications, Oxford.

43. Tuncel, G., and Nergiz, C. 1993. Antimicrobial effect of some olive phenols in a laboratory medium. Letts. Appl. Microbiol. 17:300-302.

44. Van Alfen, N. K. 1989. Molecular bases for virulence and avirulence of fungal wilt pathogens. Pages 19-32 in: Vascular Wilt Diseases of Plants. E. C. Tjamos and C. H. Beckman, eds. Springer, Berlin.

45. Van den Berg, N., Berger, D. K., Hein, I., Birch, P. R. J., Wingfield, M. J., and Viljoen, A. 2007. Tolerance in banana to Fusarium wilt is associated with early up-regulation of cell wall-strengthening genes in the roots. Mol. Plant Pathol. 8:333-341.

46. Vance, C. P., Kirk, T. K., and Sherwood, R. T. 1980. Lignification as a mechanism of disease resistance. Annu. Rev. Phytopathol. 18:259-288.

47. Wardrop, A. B. 1971. Occurrence and formation in plants. Pages 19-41 in: Lignins: Occurrence, Formation, Structure, and Reactions. K. V. Sarkanen and C. H. Ludwig, eds. Wiley Interscience, New York.

48. Whetten, R., and Sederoff, R. 1995. Lignin biosynthesis. Plant Cell 7:1001-1013.

49. Zeise, K., and von Tiedemann, A. 2001. Morphological and physiological differentiation among vegetative compatibility groups of Verticillium dahliae in relation to V. longisporum. J. Phytopathol. 149:469-475.

50. Zeise, K., and von Tiedemann, A. 2002. Host specialization among vegetative compatibility groups of Verticillium dahliae in relation to Verticillium longisporum. J. Phytopathol. 150:112-119.

51. Zeise, K., and von Tiedemann, A. 2002. Application of RAPD-PCR for virulence type analysis within Verticillium dahliae and Verticillium longisporum. J. Phytopathol. 150:557-563.

52. Zhen, X. H., and Li, Y. Z. 2004. Ultrastructural changes and location of beta-1,3-glucanase in resistant and susceptible cotton cells in response to treatment with toxin of Verticillium dahliae and salicylic acid. J. Plant Physiol. 161:1367-1377

53. Zhou, L., Hu, Q., Johannson, A., and Dixelius, C. 2006. Verticillium longisporum and Verticillium dahliae: Infection and disease in Brassica napus. Plant Pathol. 55:137-144. 